\title{
A CASE OF MAL DE MELEDA DISEASE IN CHITRADURGA - KARNATAKA
}

Parvathi C. N ${ }^{1}$, Yogendra M², Raghu M. T33, Kavyashree K. L' ${ }^{4}$, Thippareddy G. T5

\section{HOW TO CITE THIS ARTICLE:}

Parvathi C. N, Yogendra M, Raghu M. T, Kavyashree K. L, Thippareddy G. T. "A Case of Mal De Meleda Disease in Chitradurga-Karnataka". Journal of Evolution of Medical and Dental Sciences 2014; Vol. 3, Issue 65, November 27; Page: 14224-14229, DOI: 10.14260/jemds/2014/3906

ABSTRACT: Mal de Meleda is a rare autosomal recessive palmoplantar keratoderma characterized by transgradient keratoderma with associated scleroatrophy, knee changes and onychogryphosis. This case of a 20 year old girl born of second degree consanguineous marriage is reported for its uniqueness in conformity with criteria enunciated by Stulli associated with hyperkeratotic warty papules clinically fitting into Darier's disease with lip involvement. Another interesting feature being black pigmentation of fingers and nails which was due to cashew nut shell paste application mistaken for dry gangrene.

KEYWORDS: Mal de Meleda, palmoplantar keratoderma, Onychogryphosis.

INTRODUCTION: Mal de Meleda disease was first described by Stulli of Ragusa in 1826, named after Croatian island of Meleda, with wide spectrum of skin manifestations characterized by ${ }^{1,2}$ clinical features such as autosomal recessive inheritance with onset of diffuse palmoplantar keratoderma soon after birth associated with transgradience and glove and stocking keratoderma involving dorsa of hands and fingers, feet, toes, flexor aspect of wrist with sharp margin. Globally there are four reports of this clinical condition.3,4,5 The other associated features are palmoplantar hyperhidrosis, pitting, lichenoid plaques on the elbows, knees and groins, subungual keratoderma, koilonychia, dystrophy of great toe nail, progressive conical tapering of the finger tips, perioral erythema., high arched palate and corneal lesion.

CASE REPORT: A 20 year old female patient presented on 3/10/13 to the outpatient department of Dermatology Venereology and Leprosy with history of thickening of skin over palms and soles from 6 months of age. Lesions were progressive with slow involvement of dorsal aspect of palms and soles. She had pigmented rough raised grouped lesions on the elbows, knees at 6 years of age. She also had hyperpigmented hard, curved long finger and toe nails. She gave history of topical application of cashew shell paste 4 months before. She was born of $2^{\text {nd }}$ degree consanguineous marriage. Developmental milestones were normal and school performance was below average. There was no history of hearing impairment and eye problems. Two other siblings, parents and relatives did not have similar complaints.

On clinical examination she had severe anemia. The skin on palms and soles were thick, waxy and yellow with loss of dermatoglyphics. There was diffuse palmoplantar keratoderma involving bilateral palms and soles extending proximally up to wrists and dorsa of the hands and feet with welldefined margins. Few areas of erosions in the web spaces with conical tapering of the distal digits, flexion deformity due to contractures were noticed in most of the fingers. Hyperkeratotic plaques mimicking knuckle pads were seen on the proximal interphalangeal joints. Multiple well defined lichenoid papules were present on the extensor aspects of the elbows and also well-defined plaques were seen on the extensor aspects of the knee joints. All the finger and toe nails were hyper 


\section{CASE REPORT}

pigmented, hard, curved and long. Lips had dry, erythematous and depigmented plaques. Oral hygiene was bad with caries teeth with angular cheilitis and geographic tongue. Multiple, dirty, warty papules coalescing into patches symmetrically distributed over neck, trunk and flexors of the extremities mimicking Darier's disease. Hairs were normal. Histopathology of the palmar skin showed hyperkeratosis, hypergranulosis and acanthosis. Skin over the lower back showed hyperkeratosis, acanthosis, papillomatosis with no evidence of Darier's disease.

DISCUSSION: The diagnosis of palmoplantar keratoderma is complex and the disorder has been distinguished by mode of inheritance, sites of involvement and associated abnormalities. ${ }^{4}$

The obligatory clinical features of Mal de Meleda are:

1. Autosomal recessive inheritance,

2. Onset of diffuse keratoderma palmoplantaris soon after birth (or up to 3 years of life),

3. Transgressive and progressive nature of keratoderma which tends to involve the dorsa of hands and fingers, feet and toes, flexor aspect of the wrist ("glove and stocking keratoderma") with sharp margin. Hyperkeratotic plaques resembling knuckle pads may be seen on the interphalangeal joints.

The facultative clinical features are:

1. Palmoplantar hyperhidrosis,

2. Pitting in the keratoderma palmoplantaris,

3. Lichenoid polycyclic plaques,

4. Subungual keratosis, koilonychias, dystrophy of the great toe nail,

5. Progressive conical tapering of the fingertips which may lead to contractures of the fingers,

6. Perioral erythema,

7. High arched palate,

8. Corneal lesions. Digital constrictions (pseudoainhum) and angular cheilitis are also common.

Other rare features include lingua plicata, syndactyly, left handedness and hair on palms and soles. The involvement of the lips as was seen in both our cases is unique and hitherto unreported in the English literature. ${ }^{6}$

We made the diagnosis of Mal de Maleda based on certain features:

1. Autosomal recessive inheritance with family history of second degree consanguinity.

2. Onset during 6 months of age.

3. Characteristic glove and stocking like hyperkeratotic (transgradience) with sharp margin hyperkeratotic plaques on the knee and ankles, slow progressive without remission, sclerodactyly, knuckle pads, hyperkeratotic plaques on the lips and onychogryphosis.

1. Hyperkeratotic plaques looking like knuckle pads were present on all proximal interphalangeal joints. Similar lesions have been described in one case of hereditary epidermolytic palmoplantar keratoderma (vorner type). Our case is an example of knuckle pads associated with Mal de meleda. ${ }^{7}$ 


\section{CASE REPORT}

2. Mal de Meleda is characterized by slowly progressive transgradient, hyperkeratotic plaques on the dorsum of hands, feet, knee, elbows and medial malleoli, perioral erythema, hyperhidrosis and nail thickening or koilonychias. Other rare features include lingua plicata, syndactyly, high arched palate, left handedness and hair on palms and soles. It can be differentiated clinically from other hereditary keratoderma with diffuse involvement of palms and soles and absence of transgradience. Keratosis Palmaris et plantaris of Thost- Unna is an autosomal dominant genodermatosis in which hyperkeratosis is confined to palms and soles. The change from keratotic to normal skin in sometimes marked by a narrow red line but does not progress to glove and stocking pattern seen in Mal de Meleda. ${ }^{8}$

3. Progressive palmoplantar keratoderma (Griether's Syndrome) exhibits autosomal dominant inheritance. It can resemble Mal de Meleda but may spare palm and soles and involve other areas rather than hands and feet and tends to improve spontaneously in mid-life. Of the keratodermas with recessive inheritance, differential diagnosis was easily made both from Papillon-Lefevre syndrome in which peridontopathy always occurs and with Richner-Hanhart syndromes in which mental impairment and corneal ulcers is present. Voh Winkel's keratoderma is characterized by star shaped keratosis, fibrous bands and auto amputation. Ainhum like lesions and digital constrictions have been reported with Mal de Meleda giving rise to ugly mutiliation. ${ }^{9}$

4. Therapeutic options include urea containing moisturizers or keratolytics like salicylic acid. Etretinate was found useful in Mal de Meleda. ${ }^{10}$

5. It improves the hyperkeratosis but not the erythema and the response is dose dependent. It is recommended in the dose of $1 \mathrm{mg}$ per kg body wt over the period of few months. This drug enables the hand and feet to function acceptably with regression of ainhum. Isotretinon has also been used with promising results. High doses of vitamin A $(3,00,000$ units daily) has led to noticeable reduction in hyperkeratosis and this is maintained as long as vitamin A therapy is continued. A lower dose of vitamin A has a less satisfactory and slower response. ${ }^{11}$ This is similar to the case reported here.

CONCLUSION: This case is reported for its uniqueness in conformity with the criteria enunciated by Stulli associated with hyperkeratotic warty papules clinically fitting into Darier's disease. Another interesting feature being acquired black pigmentation of fingers and nails which was due to cashew shell paste application mistaken for dry gangrene was saved.

With emmolients and good nutrition her disability reduced to such an extent that she could perform her daily activities independently.

\section{REFERENCES:}

1. Niles HD, Klumpp MM. Mal de Maleda- review of literature and report of four cases. Arch Dermatol Syphilol 1939, 39:409-21.

2. Deepika Pandhi, BSN Reddy. Mal de Meleda type of keratoderma. Indian J Dermatol 2001; 46 (4). 


\section{CASE REPORT}

3. Jude MR, McLean WH, Munro CS. Disorders of keratinization. In: Burns T, Breathnach S, Cox N, Griffiths C, editors. Rook's Textbook of dermatology, $8^{\text {th }}$ ed.Singapore: Wiley-Blackwell; 2010.p.19.93-19.119.

4. Amiya Kumar Nath, Sangitha Chaudhuri, Devinder Mohan Thappa. Mal de Meleda with lip involvement: A Report of two cases. Indian journal of dermatology 2012; 57 (5).

5. Thappa DM. Mal de Meleda type of keratoderma. Indian J dermatology 2002; 47; 196.

6. Yadav BS, Sonawane SN, Desphande RP, Palmoplantar keratoderma- Mal de Meleda type. Ind J Dermatol Venereol Leprol 1994; 60: 359-61.

7. Nogila T, et al. Hereditary epidermolytic PPK with knuckle pad like lesions over the finger joints. Br J Dermatol 1991; 125: 196.

8. Salamon T. Derberovic L, Topic B, et al. Mal de Meleda. Data and remarks on a series. J Ital Dermatol Venereol 1988, 123:649-55.

9. Sybert VP, Dale BA, Holbrook KA, palmoplantar keratoderma. A clinical; ultrastructural and biochemical study. J Am Acad Dermatol 1988; 18: 75-86.

10. Bramilla L, Pigatto PD, Boneschi V. unusual cases of Mal de Meleda keratoderma treated with aromatic retinoid, etretinate. dermatologica 1984, 168: 283-6.

11. Brunner MJ, Fuhrman DL, Mal de Meleda. report of a case and results of treatment with vitamin A, Arch Dermatol Syphilol 1950, 61:820.

Figure 1: Transgradient palmoplantar keratoderma with sharp margins and flexion deformity.

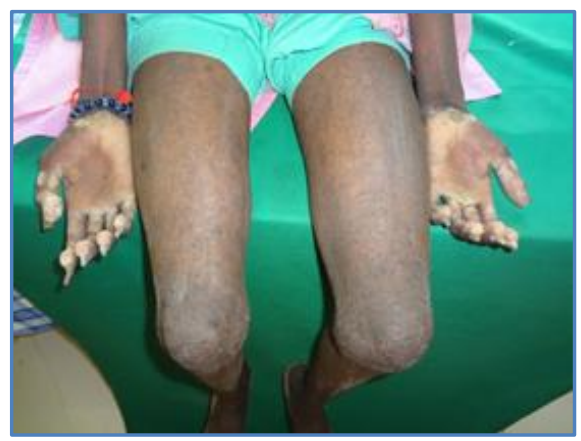

Fig. 1

Figure 2: Hyperkeratotic warty papules

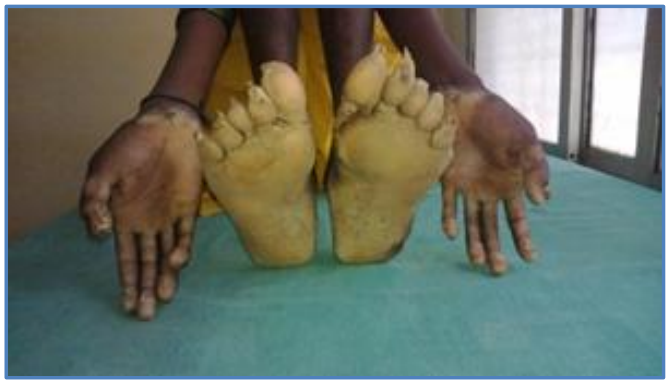

Fig. 2 


\section{CASE REPORT}

Figure 3: Palmoplantar keratoderma

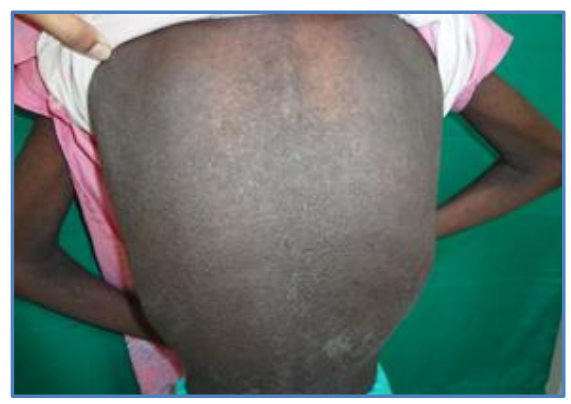

\section{Fig. 3}

Figure 4: Lip involvement with angular cheilitis.

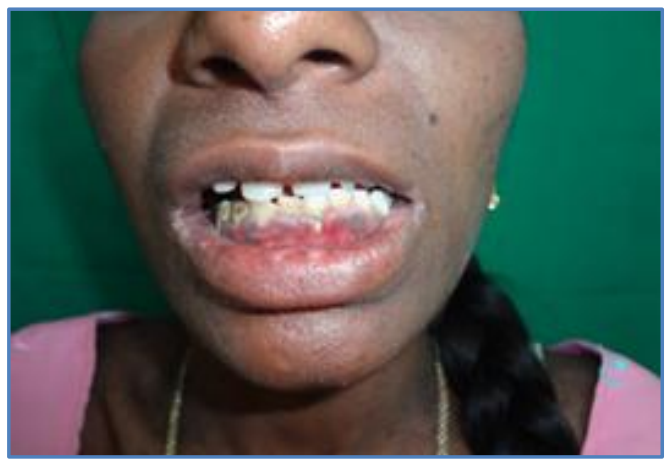

Fig. 4

Figure 5: Flexion deformity with black pigmentation due to cashew paste application with onychogryphosis (Before treatment).

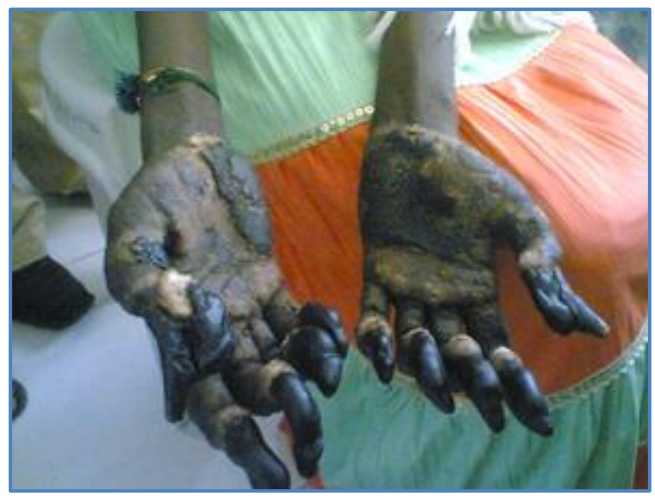

Fig. 5 
Figure 6: Flexion deformity with black pigmentation due to cashew paste application (After treatment).

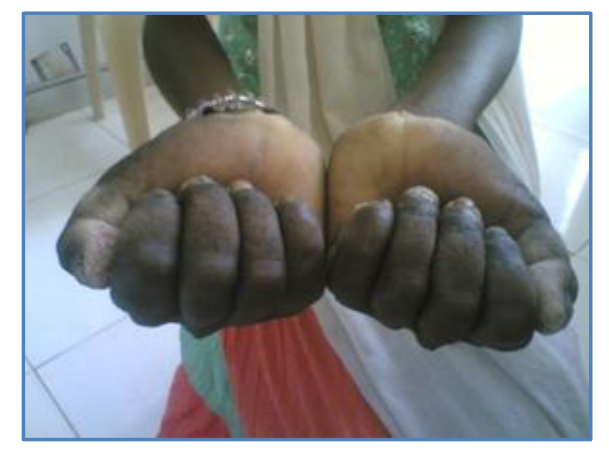

Fig. 6

\section{AUTHORS:}

1. Parvathi C. N.

2. Yogendra $\mathrm{M}$.

3. Raghu M. T.

4. Kavyashree K. L.

5. Thippareddy G. T.

\section{PARTICULARS OF CONTRIBUTORS:}

1. Professor and HOD, Department of Dermatology, BMCH \& RC, Chitradurga.

2. Professor, Department of Dermatology, BMCH \& RC, Chitradurga.

3. Assistant Professor, Department of Dermatology, BMCH \& RC, Chitradurga.

4. Senior Resident, Department of Dermatology, BMCH \& RC, Chitradurga.
5. Senior Resident, Department of Dermatology, BMCH \& RC, Chitradurga.

\section{NAME ADDRESS EMAIL ID OF THE CORRESPONDING AUTHOR:}

Dr. Parvathi C. N, Professor and HOD, Department of Dermatology, BMCH \& RC, Chitradurga.

Email: drparavathicn@gmail.com

Date of Submission: 10/11/2014.

Date of Peer Review: 11/11/2014.

Date of Acceptance: 22/11/2014.

Date of Publishing: 27/11/2014. 